\title{
ESTRUCTURA Y GESTIÓN DE LOS FONDOS DE PENSIÓN EN BRASIL
}

\author{
Joaquim Rubens Fontes Filho \\ Escola Brasileira de Administração Pública e de Empresas \\ da Fundação Getulio Vargas, Brasil
}

\section{Resumen}

El sistema brasileño de fondos de pensión alcanza la madurez después de 30 años de operación y acumulación de reservas. En este momento, distintos son los desafios y oportunidades que encuentran para su actuación, de naturaleza institucional, económica y competitiva. Este trabajo tiene como objetivo identificar cómo los fondos de pensión brasileños están operando, analizando sus prácticas de gobernanza y los principales instrumentos de gestión, y verificando cómo características como porte, patrocinio y madurez, entre otras, ejercen influencia sobre la configuración de estas prácticas e instrumentos. En la conclusión se discuten, con base en los resultados, sugerencias de acciones que puedan contribuir para el desarrollo del sistema cerrado de previsión complementaria.

Palabras claves: Sistema Previsional Brasileño, Fondos de Pensión, Gobernanza.

\section{Abstract}

The Brazilian pension fund system has reached maturity after thirty years of operation and asset accumulation. Presently, it faces many new challenges related to its working environment and its institutional, economic and competitive nature. This work presents the conclusions of research aimed to identify how Brazilian pension funds works, analyzing their governance practices and main administrative processes and verifying how different characteristics, such as size, sponsorship, maturity, influence the configuration of those practices and process. Based on the research findings, the conclusion proposes guidelines to contribute to system development.

Keywords: Brazilian Pensions System, Pensions Funds, Governance. 


\section{Introducción}

Desde mediados de la década de 1990, cuando se alcanzó el control de la inflación, el sistema de previsión privada ha presentado un significativo crecimiento en Brasil, particularmente en los planes abiertos. Las crecientes dificultades del Estado en asegurar la jubilación a un conjunto amplio de trabajadores refuerzan la necesidad de un modelo complementario que, basado en ahorros privados, consiga complementar la renta necesaria para mantener el estándar de vida post-laboral.

En el contexto macroeconómico las exigencias de un equilibrio en las cuentas públicas, en especial aquellas relacionadas con la previsión social, amplían el papel de la previsión complementaria. En particular, en el contexto de los fondos de pensión, el foco de este trabajo, las presiones por una mayor eficiencia en la gestión de los recursos y la atención a las expectativas de los participantes y patrocinadores se suman a la ampliación de la oferta de otros instrumentos de ahorro previsional para presionar estas entidades a la innovación y al fortalecimiento de la sinergia en el sector. Internamente la exigencia de adopción de mecanismos sofisticados y onerosos para la gestión de los activos y pasivos de los fondos impone costos cada vez más elevados de implantación y capacitación.

El sistema de fondos de pensión atraviesa un período de estagnación en cuanto a la creación de nuevas entidades, aunque el volumen de los activos de inversión siga aumentando. Los cambios en las reglas de tributación del sector, la creación de planes instituidos y las discusiones alrededor de la previsión complementaria del servidor público apuntan hacia un nuevo ciclo de crecimiento. Entre tanto, este sistema se acerca a su madurez, momento que exige revisar estrategias de desarrollo, principalmente para enfrentar costos administrativos declinantes y mayores gastos en los instrumentos de control. A su vez, la previsión abierta y fondos de inversión diversos ofrecen alternativas cada vez más agresivas de opciones de ahorro a largo plazo. Complementando la configuración de este escenario, cabe destacar la nueva dinámica del mercado de trabajo, con elevados índices de alternancia de los trabajadores, carreras horizontales y desvinculación de la responsabilidad por la carrera de la empresa para el propio individuo, según sus ambiciones y expectativas (Balassiano, Ventura, Fontes Filho, 2003).

Tales cuestiones configuran un cuadro de oportunidades y desafíos para aprovechar las oportunidades de desarrollo, ampliando la oferta de la seguridad previsional a un conjunto mayor de trabajadores y organizaciones con costos cada vez más reducidos y con rentabilidad creciente, seguridad y adecuación de las carteras a las nuevas exigencias del mercado de trabajo. 
Para aumentar la complejidad del momento, se introduce una variable más en el contexto brasileño: el multipatrocinio. El Instituto del Multipatrocinio, reglamentado por la Ley Complementaria 109, de 2001, autoriza a un fondo de pensión a administrar planes de diferentes empresas, ampliando la posibilidad de ganancias de escala y reduciendo costos de gestión a participantes y patrocinadores. Entre tanto, al separar el plan del fondo se crean nuevas exigencias sobre la administración de la entidad, en especial en los aspectos de su gobernanza. Del punto de vista de la gestión, la segregación en el acompañamiento de los planes, en la relación con los participantes, y a veces en el destino de los recursos financieros, exige cuidados específicos para que el tratamiento individualizado no impida la formación de sinergias que justifiquen la organización del multipatrocinio. En lo que se refiere a la gobernanza, los desafíos se relacionan con las cuestiones de representatividad en los consejos, influencia y monitoreo de la gestión, proceso decisorio y rendición de cuentas a participantes y patrocinadores.

En realidad la importancia de la discusión sobre gobernanza de los fondos de pensión trasciende el contexto nacional, siendo objeto de estudios y proposiciones, tanto de la OCDE (Organización para la Cooperación y el Desarrollo Económico), como del Banco Mundial, que la define en sus trabajos como la manera por la cual se ejerce la autoridad o el poder para cumplir sus obligaciones y deberes frente a un grupo constituido por partes interesadas (Impavido, 2002).

Ante este escenario, el presente estudio se orienta hacia la identificación y el análisis de los instrumentos que las entidades vienen utilizando para administrar las relaciones entre sus principales grupos de interés, participantes, patrocinadores y gestores, a través de la creación de esquemas de gobernanza. Su objetivo principal es presentar un diseño de la configuración del sistema brasileño de previsión complementaria cerrado, además de verificar la hipótesis de que determinadas variables, como porte, multipatrocinio, edad, origen del patrocinador y madurez, pueden estar asociadas a elecciones por diferentes prácticas de gestión y gobernanza.

La investigación tiene como objetivo comprender la configuración del sistema brasileño de previsión complementaria cerrado en lo concerniente a sus prácticas de gobernanza y gestión, verificando la influencia de características seleccionadas sobre la conformación de estas prácticas. Con base en el referencial de la teoría de la agencia, se adoptó como hipótesis central que la intensidad de la aplicación de los instrumentos de monitoreo, control e incentivos al comportamiento del agente, en el caso el gestor del fondo de pensión, estaría directamente relacionada con los riesgos y expectativas de los principales - participantes y patrocinadores 
- asociadas a las características utilizadas en el análisis, implementadas en la segmentación de la muestra.

La investigación se realizó a comienzos de 2004 y consideró como universo los 245 fondos de pensión vinculados a la Asociación Brasileña de las Entidades Cerradas de Previsión Complementaria (Abrapp), órgano de clase que congrega los fondos de pensión. Conforme datos del órgano supervisor, en este momento estaban en operación 343 entidades (SPC, 2003). La opción por limitar la investigación a los asociados de Abrapp tuvo como justificación la elevada representatividad de este agrupamiento en el total del sistema, equivaliendo a más del $90 \%$ de los activos totales y al $81 \%$ del universo de participantes, y la existencia de un registro con la dirección de las entidades, lo que permitía una mejor posibilidad de acceso. Además, los fondos de pensión que no son asociados a Abrapp tienen como característica común el ser de pequeño porte y baja representatividad económica, operando en general como estructuras virtuales y con mecanismos simplificados de gobernanza, por lo tanto de poco interés para la investigación.

De este agrupamiento de 245 fondos de pensión asociados a Abrapp se excluyeron 9 fondos, en intervención o en liquidación, y se encaminó a los demás un cuestionario dirigido al presidente ejecutivo de las organizaciones, solicitando informaciones sobre sus estructuras de gobernanza y gestión, conforme detalladas en los indicadores presentados en la tabla 2. De los 236 cuestionarios enviados 81 retornaron, configurando una muestra representativa del $72 \%$ del total de los activos de inversión del universo de la investigación y del $55 \%$ del total de participantes.

La segunda sección presenta la estructura previsional brasileña y explica qué rol tiene la participación privada. La tercera sección muestra cómo los fondos privados se han desarrollado y en cuál es su situación actual. La cuarta sección presenta la metodología del estudio y los supuestos con el que se diseñaron los instrumentos de pesquisa. La quinta sección explica cómo se trataron los datos y presenta los resultados del estudio. Finalmente, se presentan algunas conclusiones.

\section{La Estructura de la Previsión en Brasil y el Papel de la Previsión Privada}

El sistema de previsión brasileño se caracteriza por una estructura de tres pilares. El primero de ellos representa la previsión oficial, de carácter compulsorio, e incluye tanto a trabajadores autónomos y privados, en el Régimen General de la Previsión Social (RGPS), como a servidores públicos de cargo efectivo, que participan de los denominados Regímenes Propios de Previsión Social (RPPS), de la Unión, estados, Distrito Federal y municipios. En este modelo no ocurre acumulación de recursos, una vez que sigue un mecanismo de 
repartición simple, por el cual las contribuciones de los participantes activos son destinadas al pago de las jubilaciones en el período vigente (pay-as-you-go). Una diferencia fundamental en estos regímenes es que mientras en el RPPS no hay techo para la recepción de los beneficios de la previsión, en el RGPS este techo equivalía, en abril de 2007, a cerca de US\$ $1.420,00$.

El segundo pilar está representado por la previsión complementaria cerrada, que está disponible solamente para los participantes de una empresa, patrocinadora de un plan de beneficios, y más recientemente, a los asociados de un órgano de clase o similar, denominado instituidor por la Ley Complementaria 109, de 2001 (Brasil, 2001a). Usualmente los planes de esta categoría deben ser capitalizados a partir de contribuciones mensuales de participantes y patrocinadores. Los planes son administrados por una organización sin fines de lucros, constituida en la forma de fundación o sociedad civil, denominada 'Entidade Fechada de Previdência Complementar (EFPC)' [Entidad Cerrada de Previsión Complementaria], más conocida como fondo de pensión, o también fundación, dada su forma jurídica predominante. Este sistema se muestra interesante apenas para los trabajadores de la iniciada privada, vinculados al RGPS, una vez que los servidores públicos no necesitan esquema de complemento de renta en la jubilación por que no tienen techo para los beneficios y así se jubilan con el sueldo de la activa. Debe destacarse que, como lo informa el material del propio Ministerio de Previsión (Brasil, 2001c), existe hoy en el gobierno una inclinación para establecerse un techo también para el RPPS; lo que llevará a la necesidad de que se organicen fondos de previsión también para los servidores públicos. En realidad, esto no es novedad, toda vez que el gobierno sometió al Congreso Nacional, en marzo de 1999, el Proyecto de Ley Complementaria $n^{0} 9$, que atendía a la demanda de enmienda constitucional y cuyo objetivo era crear un fondo de pensión para los servidores públicos. Entre tanto, por dificultades políticas, este proyecto aún se encuentra en tramitación en la fecha, mientras que los demás proyectos vinculados a esta enmienda fueron aprobados en 2001 (Brasil, 2001a, 2001b).

El tercer pilar está representado por la previsión complementaria abierta, administrada por bancos y aseguradoras, de carácter voluntario y con reservas constituidas por los ahorros individuales. A semejanza del segundo pilar, los planes son capitalizados. En algunas situaciones una empresa puede constituir planes colectivos para sus empleados, lo que los hace similares a los administrados por los fondos de pensión.

Dos momentos pueden ser situados como determinantes para el desarrollo de la previsión privada en Brasil.

El primero de ellos ocurrió con la introducción de la legislación básica del sector, la Ley 6.435, en 1977, que estuvo en vigencia hasta 2001. Esta legislación trajo seguridad jurídica 
y definió la naturaleza de las entidades cerradas y abiertas de previsión complementaria. El segundo momento puede situarse en el año 1994, con la introducción de la nueva moneda, el Real, y el control de la inflación.

Los principales beneficiados por el advenimiento de la Ley 6.435 fueron los fondos de pensión, y particularmente, aquellos patrocinados por las empresas estatales. En la década de 1980 el sistema de fondos de pensión tuvo un gran desarrollo, lo que puede explicarse por el proceso de acumulación. Recién constituidos, tenían apenas entrada de contribuciones de participantes y patrocinadores con volúmenes mínimos de pagos de jubilaciones o pensiones. De esta forma, al iniciar la década siguiente los fondos eran detentadores de un significativo volumen de activos de inversiones, lo que les permitió participar activamente de la compra de empresas estatales que estaban siendo privatizadas y obtener ganancias significativas en las aplicaciones de renta fija, debido a las altas tasas de intereses fijadas por el Gobierno Federal, que tenía que financiar su deuda y proteger la nueva moneda. Como consecuencia, la década de 90 permitió que los fondos de pensión alcanzaran niveles de crecimiento de los activos significativamente superiores a los costos actuariales.

Las entidades abiertas de previsión complementaria poco se beneficiaron con este crecimiento. En virtud de los altos índices de inflación de la década de 80 e inicio de los años 90 , que con frecuencia superaban los $30 \%$ al mes, y de una legislación incapaz de proteger adecuadamente a los participantes de estos planes, hubo distintos problemas de insuficiencia de reservas técnicas que generaron innumerables perjudicados. Mientras que la inflación alimentaba un rechazo a las inversiones de largo plazo, percibidas como instrumentos poco adecuados para la conservación del estándar de renta en este ambiente, el problema de las reservas contribuyó para crear una imagen negativa en cuanto a la seguridad de estos planes.

De hecho, con la estabilidad de la moneda a partir de 1994 los planes abiertos reemplazaron los planes cerrados en términos de liderazgo en las tasas de crecimiento. Mientras que el número de fondos de pensión se viene manteniendo prácticamente estable en los últimos quince años, alrededor de 350 entidades, el número de planes abiertos ha tenido un elevado crecimiento. La comparación queda mejor situada cuando se examinan las tasas anuales de crecimiento de los activos de inversión de las entidades de planes abiertos y de los fondos de pensión, dado que se reduce la distorsión de la separación entre plan y entidad gestora. Como muestra el gráfico 1, los planes abiertos han mantenido tasas de crecimiento de los activos muy superiores a los planes cerrados desde 1995. 
GRÁFICO 1: Crecimiento porcentual de los activos de inversión de las entidades de previsión complementaria

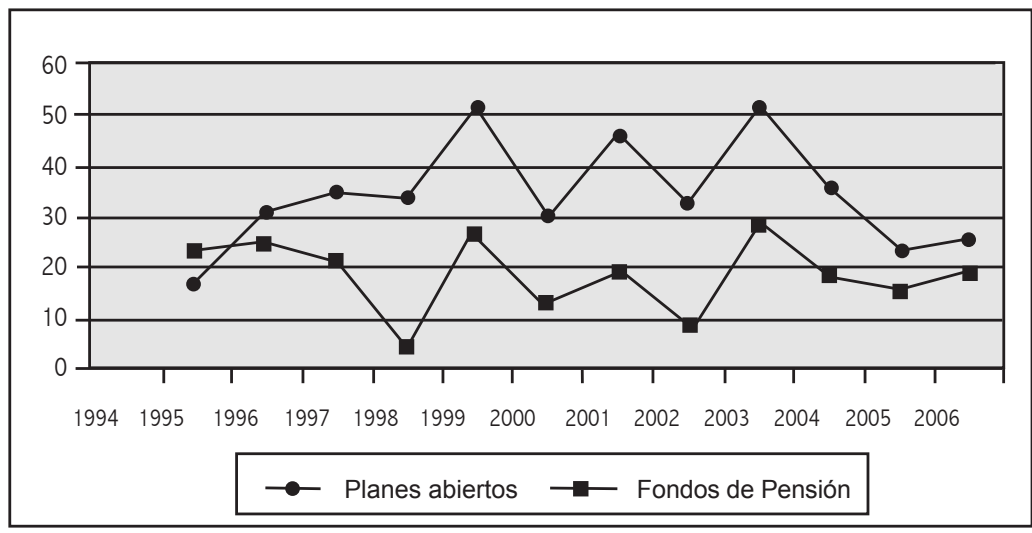

Fuente: Planes abiertos (ANAPP, en www.anapp.com.br) y Fondos de Pensión (ABRAPP, en www.abrapp.org.br).

Los elevados niveles de informalidad en el mercado de trabajo brasileño, que ya en 2002 superaban el $47 \%$, representan una dificultad adicional para los fondos de pensión, pero un amplio espacio de crecimiento de mercado para los planes abiertos, ya que la informalidad se caracteriza por trabajadores sin contrato legal, o cuentapropistas, los productos más adecuados para este contingente los ofrecen los planes abiertos, que no exigen un vínculo formal con una organización. Si observamos que de este contingente de trabajadores cuentapropistas el 82,5\% no eran contribuyentes de la previsión social en el 2004 (IPEA, 2006), el potencial de crecimiento de estos planes se hace más evidente en la medida que mejora la renta o la capacidad de ahorro de este agrupamiento.

Para los fondos de pensión, a partir del cambio de la legislación, en 2001, se autorizó la constitución de planes cerrados desvinculados de una empresa específica, disponibles para los asociados o miembros de personas jurídicas de carácter profesional, clasista o sectorial, denominadas instituidores (Brasil, 2001a). El objetivo de esta autorización era promover el crecimiento del sistema de previsión complementaria, estimulando la organización de nuevos planes, como también reducir el costo de administración de los planes previsionales para estos individuos, actuando de esta forma también sobre el equilibro del mercado.

Es importante destacar que en el mercado brasileño la previsión abierta ofrece productos de naturaleza típicamente previsional, como es el caso de la familia del denominado Plan Generador de Beneficios Libres (PGBL), pero también planes que se caracterizan como seguro de vida, con beneficios de rescate en vida de una renta programada, típicamente el Vida Generador de Beneficio Libre (VGBL). La principal diferencia entre estos productos, del punto de vista del cliente, se refiere a la tributación. El PGBL cuenta con incentivo fiscal, permitiéndose 
deducir de la base de cálculo del impuesto de renta debido las contribuciones realizadas hasta el límite del $12 \%$ de la renta bruta anual del individuo; con todo, la tributación incidirá en el momento de recibirse las contribuciones. El VGBL, por el contrario, no cuenta con ningún beneficio fiscal pero, por estar constituido sobre un ahorro creado con un recurso a principio ya tributado o exento, no obliga al asegurado a recoger impuestos cuando recibe el beneficio. Como informa el propio sitio de la asociación del sector (www.anapp.com.br), es un producto dirigido hacia aquellos que actúan en la economía informal o no pueden obtener los beneficios fiscales, sea por que están exentos del impuesto a la renta en virtud de ingresos bajos, sea porque ya usufructúan del máximo de exención en otros planes de jubilación.

Es significativo observar que mientras la contribución del VGBL en la cartera de inversiones de las entidades abiertas pasó del 19,8\% para el 41,8\% entre diciembre del 2003 y marzo del 2007, el PGBL tuvo un crecimiento mucho menor que el de esta contribución, del 24,8\% para el 27,1\% (FENAPREVI, 2001), números que demuestran la adecuación del VGBL a las características y necesidades del mercado brasileño. Considerando que este plan no autoriza beneficios fiscales, este crecimiento puede sorprender. Entre tanto, el gran contingente de trabajadores informales en el país, sumado a aquellos que tienen ingresos inferiores a los definidos para tributación mínima en el impuesto a la renta, representan un segmento expresivo de mercado; además, la gran mayoría de estos individuos está fuera de la posibilidad de participar de un plan de previsión cerrado.

La cartera de Inversiones de las entidades abiertas de previsión complementaria - que incluye las reservas técnicas, las reservas libres, el capital de aseguradoras y otros valores - se elevaba en marzo de 2007 a US\$ 52.190 millones, valor que representa cerca del 30\% del volumen de los activos de inversiones de los fondos de pensión, que en este mismo mes fue de US\$ 178.190 millones. Un crecimiento significativo, si se considera que en 1995 representaban apenas el 6\% (FENAPREVI, 2001).

Empresas como bancos y aseguradoras ofrecen a la población en general planes abiertos. Los planes cerrados son administrados por fondos de pensión, para una población específica, tienen vínculos con una organización patrocinadora que, en esta condición, se hace responsable por parte de las contribuciones para la formación de las reservas; asimismo, permiten la figura del instituidor, que apenas organiza el plan, no haciendo ninguna contribución. La principal diferencia es que los fondos de pensión son entidades sin fines lucrativos mientras que los planes abiertos son administrados por sociedades anónimas.

Es particularmente significativo para los objetivos de este estudio observar que los fondos de pensión deben seguir reglas de cogestión entre los trabajadores y las organizaciones 
patrocinadoras. En conformidad con la legislación complementaria que rige a este sistema, los fondos de pensión deben tener un tercio de sus consejos deliberativo y fiscal formado por representantes de los participantes (BRASIL, 2001a); en el caso de fondos patrocinados por órganos públicos o empresas estatales este porcentaje debe ser del 50\% (Brasil, 2001b).

\section{Los Fondos de Pensión: Desarrollo y Situación Actual}

A partir de la Ley 6.435, de 1977, que reglamentó el sistema de previsión privada en Brasil, los fondos de pensión iniciaron un activo proceso de crecimiento. Actualmente, según datos de la Secretaría de la Previsión Complementaria, órgano del Ministerio de la Previsión y responsable por la supervisión del sector, hay en operación en el país 354 fondos de pensión, que administran planes de 2205 organizaciones patrocinadoras, siendo que 292 son patrocinados por entes públicos y 1913 por privados, y que atienden a 1,8 millones de participantes activos y a 600 mil asistidos y pensionistas (SPC, 2006).

El sector está regulado por dos leyes complementarias fundamentales, promulgadas en 2001, la Ley Complementaria 109, que dispone sobre el régimen de previsión complementaria en general y que vino reemplazar la Ley 6.435 , normando, incluso, los planes abiertos, y la Ley complementaria 108, que dispone específicamente sobre las relaciones de los órganos y empresas del poder público y los fondos de pensión en que patrocina planes de beneficio. La regulación del sistema es de responsabilidad del Consejo de Gestión de la Previsión Complementaria - CGPC, que tiene también funciones de órgano para presentación de recursos y está compuesto por ocho miembros representantes del Gobierno (Ministerios de la Previsión, Hacienda y Planificación), de los fondos de pensión, de participantes y asistidos de los planes, y de patrocinadores e instituidores de planes de previsión.

Conforme a la Ley Complementaria 109, cabe al Consejo Monetario Nacional normar la aplicación de los recursos correspondientes a las reservas, provisiones y fondos de las entidades de previsión complementaria cerradas y abiertas. En el sistema cerrado de los fondos de pensión estas aplicaciones están normadas por la Resolución 3.456, de $1^{\circ}$ de junio de 2007, que discrimina los activos con inversiones autorizados y los porcentajes de aplicación. Es importante registrar que la Ley Complementaria 109 vetó el establecimiento de aplicaciones compulsorias o límites mínimos de aplicación a las entidades, lo que contribuyó significativamente para mejorar la seguridad del sistema.

En marzo de 2007 el total de activos de inversiones del sistema de fondos de pensión en Brasil era del orden de los US\$177.000 millones, valores cercanos al 17\% del Producto Interno Bruto del país. El gráfico 2 presenta la evolución de estos activos con relación al PIB, 
con base en los datos de la asociación que congrega a las organizaciones del sector, la Asociación Brasileña de las Entidades Cerradas de Previsión Complementaria (Abrapp).

GRÁFICO 2: Evolución de la relación de los activos de los fondos de pensión sobre el PIB

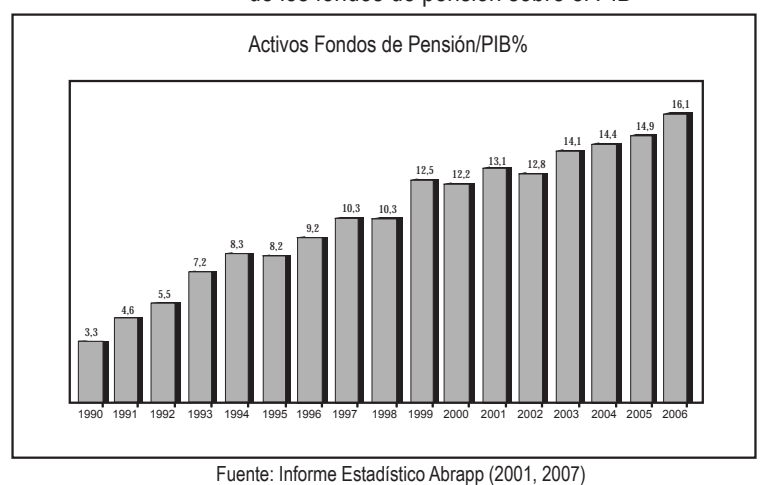

Conforme a la Resolución 3.456 del Conselho Monetário Nacional, los recursos que garantizan los planes de beneficios de las entidades cerradas de previsión complementaria pueden ser destinados a cuatro segmentos: renta fija, renta variable, inmuebles, o préstamos y financiaciones a participantes. Los límites máximos para la aplicación de los recursos que garantizan en cada uno de estos segmentos son del $100 \%$ en la renta fija, del $50 \%$ en la renta variable, del $11 \%$ en inmuebles (reducido al $8 \%$ a partir de enero de 2009), y del $15 \%$ en préstamos y financiación inmobiliaria a los participantes y asistidos de los planes, siendo que las obligaciones financieras de estas operaciones no pueden ser inferiores a la tasa mínima actuarial o al índice de referencia de la política de inversiones, más el costo administrativo y operacional, de acuerdo con la modalidad del plan de beneficios. Además de estos limites superiores, agregados, la Resolución 3.456 detalla una serie de sublímites y condiciones para inversiones en activos específicos en cada segmento, y no autoriza inversiones directas en el exterior, salvo pequeños porcentajes autorizados en títulos como Brazilian Depositary Receipts (BDRs).

Desde mediados de la década de 1990 los fondos vienen ejerciendo un papel fundamental en el cambio de la estructura de capital de las empresas brasileñas, principalmente como consecuencia de una activa participación en la privatización de empresas estatales motivada por su interés en la diversificación de sus portafolios de inversiones. Aunque la participación en el capital de una empresa sea legalmente limitada al $20 \%$ del capital votante, este monto es suficiente para permitir su inserción en el grupo controlador. A título de ejemplo, la 'Caixa de Previdência dos Funcionários do Banco do Brasil (PREVI)' [Caja de Previsión de los Empleados del Banco de Brasil], el mayor fondo de pensión brasileño, posee acciones que 
representan parcela de control en más de 90 grandes empresas nacionales, como la 'Companhia Vale do Rio Doce', 'Embraer', y 'Perdigão'. A consecuencia de estas participaciones, los fondos de pensión han tenido un papel decisivo como propagadores de las buenas prácticas de gobernanza corporativa.

De forma agregada, las inversiones de los fondos de pensión están dirigidas mayoritariamente hacia el segmento de renta fija, con el 62,1\% del total de los activos de inversión del sistema, situación justificada básicamente por el atractivo de las elevadas tasas de intereses de los títulos públicos practicadas en la última década. De las inversiones restantes, el 32\% están aplicadas en renta variable, el 3,2\% en el segmento inmobiliario y el 2,5\% en préstamos y financiaciones a participantes (SPC, 2006).

Estos datos no permiten, con todo, comprender exactamente la situación de la composición de las carteras de los fondos en virtud de la alta concentración de los activos del sistema, una vez que, segun datos de SPC (2006) el 51,8\% de estos activos están en manos de los 10 mayores fondos patrocinados por empresas estatales. Retirando de la muestra a PREVI, el mayor fondo del país, que concentra el $31 \%$ de los activos del sistema y tiene el $67 \%$ de sus inversiones en renta variable, actualmente en proceso de reencuadramiento, el porcentaje invertido por el sistema en esta modalidad de activos cae para apenas el $16 \%$. Considerando, entonces, que el sistema está lejos de alcanzar los limites autorizados para inversiones en renta variable y que las tasas de intereses practicadas en el país vienen entrando en un consistente proceso de reducción, se espera una sustancial migración de las aplicaciones en renta fija para las de renta variable en los próximos años.

Presentando el lado del pasivo, los fondos de pensión administran planes en las modalidades de Contribución Definida (CD), Beneficio Definido (BD) e híbridos. Planes CD son semejantes a los fondos de inversión financiera y demás productos financieros, en los que el ahorro mensual se capitaliza, siendo que el valor acumulado se transforma en una renta vitalicia. En esta modalidad de plan los participantes pueden fácilmente evaluar sus inversiones, e indirectamente, la de la gestión del fondo. En los planes BD, por el contrario, la meta es una renta futura y el valor de la mensualidad puede oscilar para alcanzar esta meta, exigiendo para su planificación el desarrollo de cálculos actuariales más complejos. Una tercera posibilidad se caracteriza por los denominados planes híbridos, que son, en realidad planes CD en los que hay mecanismos de seguro asociados. Tanto en los planes BD, como en los híbridos, es mucho más difícil para los participantes entender los resultados, lo que probablemente debe influenciar en las prácticas de gobernanza.

La legislación separa la figura de la entidad de previsión complementaria cerrada y la de los planes que administra. Se permite, por ejemplo, que una entidad agregue distintos planes 
de una misma organización, todos con independencia patrimonial (multiplan); se permite también la existencia de distintos patrocinadores bajo la misma entidad (multipatrocinio), resguardada también la independencia entre los planes (Brasil, 2001a, art. 34).

Al comienzo de su historia, la mayoría de los fondos de pensión constituidos en Brasil tenía como patrocinador a una empresa o a una organización estatal. Durante muchos años la modalidad predominante de plan era la de beneficio definido, y apenas en la década de 1990 se intensificó la creación o migración para planes de contribución definida. De acuerdo con datos de la SPC de comienzos de la década (base dic/2001 - presentación en seminario OECD, en São Paulo), el porcentaje de planes CD y BD se igualaba en el $42 \%$, y los $16 \%$ restantes eran representados por los planes mixtos, aunque ya se podía observar un movimiento de migración. En una investigación realizada junto a empresas farmacéuticas internacionales que operan en el país, Delboni (2003: 179) notó que aquellas que habían implementado sus planes de beneficio hacía más de 10 años habían optado por el modelo BD, por inspiración del diseño de la matriz, mientras que en las empresas en las que el plan era de implantación reciente, la opción había sido por la modalidad CD, y no se había pensado sobre el tipo BD.

Esta historia de formación del ahorro de los fondos de pensión tiene como consecuencia que los fondos, ahora, 30 años después de la Ley 6.435, estén alcanzando su madurez, fase en que los recursos destinados a los pagos de jubilaciones y pensiones superan aquellos destinados a las contribuciones. Dado que el sistema se capitaliza, esto no representa un problema, aunque exige un mayor cuidado en la administración de activos y pasivos, equilibrándose, tanto el monto de los recursos, como la liquidez. El gráfico 3 muestra que desde 2003 los gastos previsionales ya superaron el volumen de contribuciones para el sistema, además de apuntar hacia la ampliación de esta diferencia.

GRÁFICO 3: Evolución de las contribuciones y gastos previsionales de los fondos de pensión ( $R \$$ mil millones - valores nominales)

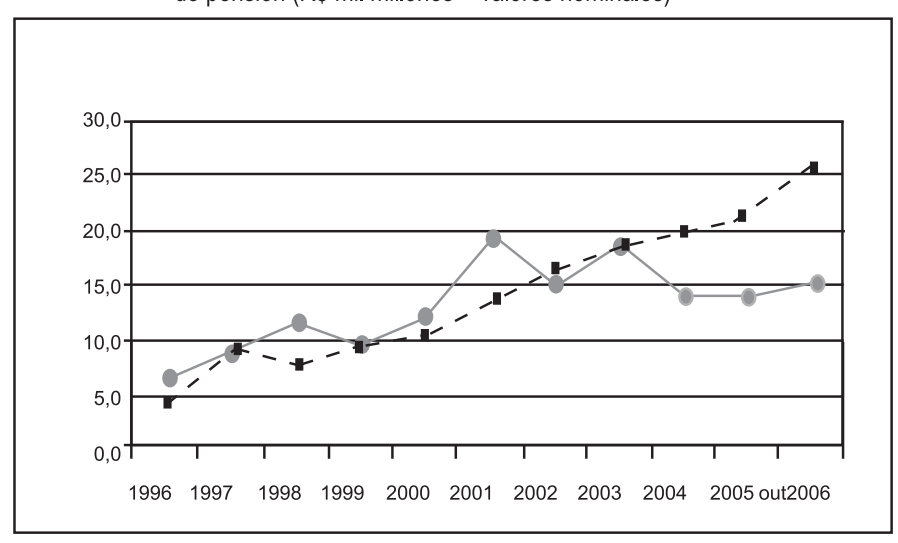

Fuente: SPC $(2006,2004)$ 
Este momento de madurez se suma a otro movimiento, el de la separación entre patrocinadores y entidades, provocada por el multipatrocinio, para configurar un punto de inflexión del sistema. Cada vez más las empresas optan por patrocinar planes para sus empleados en fondos de pensión ya constituidos, lo que fortalece la separación de la administración del plan y de la entidad. Un fondo de pensión, aún hoy, en la mayoría de las veces asociado a una empresa específica, ha sido cada vez más caracterizado como un administrador de planes de distintas empresas patrocinadoras. Con esto se vuelven mucho más complejas la gestión de planes diversos, con sus exigencias particulares de equilibrio de activos y pasivos, y la administración de los intereses e influencia de participantes y patrocinadores de cada plan. Incluso en el caso del fondo de pensión con un único patrocinador, la madurez puede hacer crecer el conflicto entre activos y asistidos en cuanto a las características de la financiación del plan y a la distribución de los beneficios.

La complejidad en el tratamiento de estas cuestiones de gestión y gobernanza se agrava aún más por el mayor volumen de recursos administrado por los fondos y por el crecimiento del número de participantes, factores que pueden atraer intereses de grupos externos a la organización y contribuir para la politización del proceso decisorio y para el mayor asedio de los gestores de recursos y de los administradores de pasivo.

\section{Los mecanismos de monitoreo, control e incentivos de los Fondos de Pensión en Brasil}

La decisión de una empresa de ofrecer un plan de pensión a sus empleados no debe ser caracterizada como una política de asistencialismo, una vez que su objetivo, por encima de todo, es agregar atractivos a su política de recursos humanos y facilitar la adopción de medidas eventualmente necesarias a la adecuación de sus cuadros, tales como demisiones incentivadas y jubilaciones anticipadas para la renovación de los cuadros. Para los empleados este es ciertamente un beneficio importante, porque trae seguridad a su vida personal.

Cabe a estos dos grupos - patrocinadores y participantes - la responsabilidad, delegada incluso por la legislación, de construir e implantar las estructuras y prácticas de gobernanza de la entidad, definiendo el proceso decisorio y los mecanismos de monitoreo, control e incentivos, acompañando las actividades de los gestores, y observando el alcance de los resultados, el desempeño de los procesos y la atención a sus expectativas. Particularmente, cabe al patrocinador actuar activamente junto a la gestión del fondo con el objetivo de asegurar la eficacia de la gestión y la adecuación de las políticas de la entidad a sus prácticas de gestión de personas. Aunque se pueda argumentar por los beneficios de la especialización en la contratación de los gestores de los fondos, es práctica del sector la utilización de dirigentes 
de la patrocinadora dislocados - en tiempo parcial o integral - para la administración del fondo de pensión. Es frecuente también que fondos de pensión con menor volumen de activos tengan un carácter casi virtual, utilizando la propia estructura de la patrocinadora, aunque contablemente segregados. Otra característica es la fuerte tercerización de la administración de los activos y pasivos en las organizaciones menores, lo que desgrava aún más la necesidad de instalaciones y recursos permanentes de la entidad.

Como consecuencia, se establece en la estructura de gobernanza de un fondo de pensión una o más relaciones de agencia, sea entre beneficiarios y patrocinadores, entre patrocinadores y gestores, o también entre beneficiarios y gestores. Se justifica, por lo tanto, la necesidad de desarrollar prácticas de gobernanza adecuadas para ocuparse con estos intereses y relaciones de forma óptima para las partes involucradas. Por definición estas relaciones envuelven un beneficiario o propietario de un activo, definido como principal, y aquellos que actúan en su beneficio, denominados agentes.

Debe también observarse que, como es frecuente en los fondos de pensión, en las situaciones en que existen distintos planes o patrocinadores vinculados a un mismo fondo ocurre la formación de una relación de múltiplos principales frente al mismo conjunto de agentes, dificultando o haciendo más costosos los procesos de deliberación estratégica. A consecuencia de todo este contexto las relaciones de agencia en un fondo de pensión no son tan directas como en una empresa privada, acarreando exigencias adicionales a los sistemas de monitoreo, control e incentivos.

Los fondos de pensión en Brasil tienen naturaleza jurídica autónoma en relación con la patrocinadora. Son entidades de derecho privado, sin fines lucrativos. Por la definición de Fama y Jensen (1983), organizaciones sin fines lucrativos no tienen residuos de caja enajenables (residual claims) que podrían ser incorporados por los socios. Entretanto, los planes BD permiten que patrocinadores y participantes sean beneficiados por resultados positivos de las operaciones, básicamente por la reducción del valor de las contribuciones, mientras que los planes de contribución definida, por seguir un proceso de capitalización semejante al de una libreta de ahorro, permiten un mayor valor futuro de los beneficios (Brasil, 2001a: art. 20). Ambas modalidades presentan, por lo tanto, al menos en parte, una apropiación por el principal de los residuos de caja de los planes.

En términos de relaciones de agencia, el patrocinador desempeña muchas veces un papel ambiguo en este sistema. Para la OECD (Yermo y Marossy, 2002), un fondo de pensión se caracteriza como una relación entre participantes, entendidos como los beneficiarios de la relación, y por lo tanto, definidos como principal, y gestores y patrocinadores, los agentes. 
Esta clasificación, entre tanto, puede obscurecer el papel de los patrocinadores, una vez que éstos también son beneficiarios de las actividades del fondo en el caso de los planes BD, por haber capturado parte de las ganancias residuales de la actuación del fondo, dada por la reducción de los valores de contribución, a diferencia de lo que ocurre cuando patrocinan planes CD. Incluso en los planes CD, en los cuales hay un riesgo mínimo, el patrocinador también ejerce una función de monitoreo y control del gestor, una vez que el fondo de pensión es legalmente una entidad externa, jurídicamente independiente de este patrocinador. Por lo tanto, es mejor caracterizarla como una relación múltiple de agencia, en la que tanto participantes como patrocinadores ejercen el papel de principal.

En el modelo CD el riesgo de los patrocinadores está asociado fundamentalmente con el impacto negativo en la imagen de la empresa en caso de desempeño insuficiente del plan, no habiendo riesgos de naturaleza financiera. Lo opuesto ocurre en los planes BD, ya que el riesgo del plan se comparte entre participantes y patrocinadores, aunque sobrecarga principalmente a este último, que debe registrar en sus balances las deudas referentes a contribuciones no realizadas, o déficit actuarial del plan. El desempeño sigue reglas actuariales complejas que dificultan a los participantes, y al propio mercado, tener una clara noción de lo que ocurre en el plan, exigiendo de los patrocinadores esfuerzos considerables para el monitoreo y el control. La confianza en la gestión se vuelve crítica, siendo importante buscar permanentemente la legitimidad ante este público para la sustentación "moral y política" de las acciones.

Al contrario del comportamiento de los accionistas, el participante de fondos de pensión tiene una predisposición menor al riesgo y mayores dificultades de ejercer movimientos de salida del negocio. En caso de no estar satisfecho en su relación con el fondo de pensión puede llegar a abandonar esta relación, pero sus costos serán elevados, principalmente porque podrá perder parte de la parcela del funding constituida por el patrocinador. Su apetito por el riesgo también es menor, porque ha ingresado en el plan de previsión una parcela significativa de su ahorro de largo plazo y tiene poca posibilidad de diversificar significativamente este riesgo, una vez que también así perdería el ahorro constituido por el patrocinador.

La denominada teoría de la agencia ha venido tratando estos problemas resultantes de la separación entre beneficiarios (propietarios) y gestores. Esta teoría considera que cabe al principal, por medio de mecanismos de monitoreo y control, asegurar que el agente actuará en su beneficio y que esquemas de incentivo también puedan utilizarse para alinear su interés con el del principal. Tomando por base las presuposiciones de la teoría de la agencia (Eisenhardt, 1989), se consideró en este estudio que estas características - el volumen de activos, el tipo de plan, el origen del patrocinador y la madurez, entre otras - podrían ayudar a entender 
la utilización de los instrumentos previstos por esta teoría para la gobernanza de las organizaciones, particularmente en lo que se refiere al monitoreo, control yçTres criterios se utilizaron para la segmentación de la muestra, según las especificidades de estas características. En los casos en que había una segmentación natural, como en las categorías tipo de plan predominante y origen del patrocinador, esta fue utilizada. Un segundo criterio tomó por base la mediana de la distribución obtenida en la muestra; es lo que ocurrió con el volumen de activos, el tiempo de existencia del fondo y la madurez. Esta característica fue operacionalizada como la relación entre el número de participantes activos dividido por la suma de los asistidos y pensionistas, y se calculó con base en las informaciones oficiales de la Secretaría de Previsión Complementaria (SPC, 2003). El tercer criterio, basado en la intencionalidad, se utilizó para las categorías relativas al número de patrocinadores y al número de planes. En el primer caso se estableció una categoría para 1 o 2 patrocinadores y otra para la situación de 3 o más patrocinadores, teniendo en vista que varios fondos se consideran patrocinadores de los planes del personal de su cuadro propio. En lo que concierne al número de planes, la diferencia buscada era entre los fondos que administran apenas un plan, o varios planes, visto ser esta situación una complicación adicional en las relaciones de agencia de los fondos de pensión.

Para facilitar la presentación de los resultados de la investigación estas características que fueron la base de la segmentación se presentan bajo la forma de siglas. La tabla 1 muestra las siglas utilizadas y los criterios considerados en estas características para la segmentación de la muestra, utilizada para efectos de la comparación en cuanto al uso de las prácticas de gobernanza.

TABLA 1: Abreviaturas y criterios de segmentación utilizados

\begin{tabular}{|c|c|}
\hline PLAN - & 1. BD - Beneficio Definido \\
\hline Modalidad de plan predominante & 2. CD - Contribución Definida o mixto \\
\hline ORIG - & \multirow{2}{*}{$\begin{array}{l}\text { 1. FPP - Fondo con patrocinador privado } \\
\text { 2. FPE - Fondo con patrocinador estatal }\end{array}$} \\
\hline $\begin{array}{l}\text { Origen del patrocinador principal del } \\
\text { fondo de pensión }\end{array}$ & \\
\hline ACTIV - & \multirow{2}{*}{$\begin{array}{l}\text { 1. Pequeño: activos inferiores a } R \$ 299.448 .354 \\
\text { 2. Grande: activos iguales o superiores a } R \$ 299.448 .354\end{array}$} \\
\hline Volumen de activos de inversiones & \\
\hline NÚM - & \multirow{2}{*}{$\begin{array}{l}\text { 1. Simple - fondos con hasta } 2 \text { patrocinadores } \\
\text { 2. Multi - fondos con } 3 \text { o más patrocinadores }\end{array}$} \\
\hline Número de patrocinadores & \\
\hline EDAD - & \multirow{2}{*}{$\begin{array}{l}\text { 1. Nuevo - hasta } 21 \text { años de existencia } \\
\text { 2. Antiguo - con } 22 \text { años o más de existencia }\end{array}$} \\
\hline $\begin{array}{l}\text { Tiempo de existencia del fondo de } \\
\text { pensión }\end{array}$ & \\
\hline MADU - & \multirow{2}{*}{$\begin{array}{l}\text { 1. Maduro - relación activo / (asistido + pensionista) } \\
\text { hasta 3,71 (mediana de la muestra) } \\
\text { 2. En Desarrollo- relación activo / (asistido + pensionista) } \\
\text { mayor que 3,71 }\end{array}$} \\
\hline $\begin{array}{l}\text { Madurez de los planes } \\
\text { administrados }\end{array}$ & \\
\hline
\end{tabular}


Se construyó un cuestionario con base en preguntas sobre las prácticas de gobernanza y la gestión de los fondos, según las dos categorías analíticas, presiones de patrocinadores y participantes, y percepción de los gestores.

La primera categoría, definida como "Presiones de Patrocinadores y Participantes", configura el conjunto de los instrumentos y procesos utilizados por participantes y patrocinadores para ejercer influencia sobre la entidad y controlar la actuación de los gestores. Esta categoría fue subdividida en tres grupos, todos relacionados con la existencia o no de herramientas y prácticas de gobernanza en el fondo de pensión. El primero de estos grupos representa los instrumentos de monitoreo y control utilizados por los patrocinadores frente a los gestores del fondo de pensión, o indirectamente por los participantes por medio de sus representantes en los consejos. El segundo considera el ejercicio de la influencia directa de los participantes en la gestión de la entidad, configurado por la existencia de organizaciones de asociados cuyo fin específico es ejercer influencia sobre las decisiones del fondo de pensión. El tercer grupo, denominado control indirecto, expresa la capacidad de control del patrocinador sobre la fundación por la utilización de mecanismos indirectos de influencia en la gestión, tales como vinculación del gestor a sus cuadros funcionales, asunción de los costos administrativos y exigencia de comités.

La segunda categoría, denominada "Percepción de Control por el Gestor", refleja su evaluación personal en cuanto a los efectos de los controles ejercidos por el principal. Esta categoría fue también desmembrada en tres grupos, control directo del patrocinador, influencia del participante, e influencia de otras organizaciones. El primer grupo representa el nivel de control percibido por el gestor sobre sus acciones y autonomía, resultante de la utilización de mecanismos de monitoreo ejercitados por patrocinadores y participantes. El segundo registra la percepción del gestor relativamente a la capacidad de influencia de los participantes sobre la gestión. El tercer grupo, la influencia de otras organizaciones, tiene el objetivo de identificar la importancia que los gestores atribuyen a resultados y prácticas de otras organizaciones que desempeñan actividades semejantes, tales como entidades de previsión abierta, fondos de inversión u otros fondos de pensión, sobre su actuación, en lo que se caracteriza como una proxy de control externo.

El cuestionario de la investigación fue operacionalizado por los indicadores descritos en la tabla 2, caracterizados como preguntas de naturaleza si/no propuestas para el contestador, a quien cabría señalar la existencia o no del instrumento o práctica mencionada. A su vez estos constructos representaban los elementos conceptuales de una categoría analítica propuesta por la teoría de la agencia. La tabla 2 presenta el desmembramiento de la categoría analítica, sus constructos y los respectivos indicadores: 
TABLA 2: Categorías analíticas, constructos e indicadores utilizados

\begin{tabular}{|c|c|c|}
\hline $\begin{array}{l}\text { CATEGORÍA } \\
\text { ANALITICA }\end{array}$ & $\begin{array}{c}\text { DIMENSIÓN } \\
\text { (CONSTRUCTO) }\end{array}$ & Indicador \\
\hline \multirow{18}{*}{ Presiones del principal } & \multirow{8}{*}{ Mecanismos de monitoreo } & Existencia de planeamiento estratégico \\
\hline & & Metas exclusivamente financieras en el planeamiento \\
\hline & & Mecanismo formal de evaluación del gestor \\
\hline & & Elección del actuario sujeta a aprobación \\
\hline & & Elección de consultoría actuarial sujeta a aprobación \\
\hline & & Elección de gestores financieros sujeta a aprobación \\
\hline & & Tipos de informes encaminados a la patrocinadora \\
\hline & & Ocurrencia de auditorias además de las legales \\
\hline & \multirow[t]{3}{*}{ Influencia de los participantes } & $\begin{array}{l}\text { Relación entre consejeros deliberativos representantes de los } \\
\text { participantes y del patrocinador }\end{array}$ \\
\hline & & $\begin{array}{l}\text { Relación entre directores representantes de los participantes y del } \\
\text { patrocinador }\end{array}$ \\
\hline & & Existencia de asociación de los participantes \\
\hline & \multirow[t]{4}{*}{ Control indirecto } & Forma de costeo de los gastos administrativos \\
\hline & & Origen del primer gestor del fondo de pensión \\
\hline & & Dedicación del primer gestor del fondo de pensión \\
\hline & & Existencia de comités previos a la deliberación de la dirección \\
\hline & \multirow[t]{3}{*}{ Incentivo } & Uso de política de participación en los resultados para gestores \\
\hline & & Elementos de la política de participación en los resultados \\
\hline & & Importancia de la política de participación en los resultados \\
\hline \multirow{9}{*}{ Percepción de control } & \multirow[t]{2}{*}{ Percepción del monitoreo } & Análisis por el consejo deliberativo de los informes \\
\hline & & Análisis del consejo fiscal de los informes \\
\hline & \multirow{2}{*}{$\begin{array}{l}\text { Percepción de la influencia de } \\
\text { los participantes en la gestión }\end{array}$} & Conocimiento de los participantes de los resultados financieros \\
\hline & & Conocimiento de los participantes de la gestión del fondo \\
\hline & \multirow{5}{*}{ Control externo por el mercado } & Acompañamiento e influencia de los participantes en la gestión \\
\hline & & Intensidad de las presiones de la asociación de participantes \\
\hline & & Posibilidad de evaluación del gestor del fondo por los pares \\
\hline & & Posibilidad de evaluación del gestor del fondo por el mercado \\
\hline & & Condiciones del mercado de evaluar el desempeño del gestor \\
\hline
\end{tabular}

\section{Resultados de la Investigación}

En la distribución de los 81 cuestionarios contestados hubo una mayor participación porcentual de fondos patrocinados por entes estatales que la existente en el universo, lo que podría eventualmente introducir distorsiones en los análisis de ciertas características. La segmentación de la muestra alrededor de la mediana, y no de la media, para las características, se utilizó como forma de minimizar este sesgo. En los análisis subsiguientes serán presentadas consideraciones adicionales al identificarse una situación que configure influencia de esta desviación en la representatividad de la muestra sobre los resultados.

De los 81 fondos que contestaron y que compusieron la muestra, 40 afirmaron que el plan predominante era el de BD, 39 el de CD o mixto, y en 2 casos no había un plan predominante. La mediana para los activos de inversión fue igual a $\mathrm{R} \$ 299,4$ millones. Las tablas de 1 a 5 presentan informaciones adicionales sobre la muestra, siendo que el tiempo en el cargo del gestor considera apenas los años completos. 
TABLA 3: Perfil de la muestra - caracterización del fondo de pensión

\begin{tabular}{|c|c|c|c|c|}
\hline & $\begin{array}{l}\text { Número de } \\
\text { patrocinadores }\end{array}$ & $\begin{array}{l}\text { Tiempo de existenci a } \\
\text { de EFPC (años) }\end{array}$ & $\begin{array}{l}\text { Tiempo en el } \\
\text { cargo del gestor }\end{array}$ & $\begin{array}{l}\text { Número de planes } \\
\text { administrados }\end{array}$ \\
\hline Promedio & 6,9 & 21,3 & 4,3 & 3,2 \\
\hline Moda & 2,0 & 24,0 & 0 & 1,0 \\
\hline Desviación Estándar & 11,8 & 12,8 & 4,0 & 5,1 \\
\hline Mínimo & 1,0 & 1,0 & 0 & 1,0 \\
\hline Máximo & 63,0 & 99,0 & 18,0 & 31,0 \\
\hline \multirow[t]{3}{*}{ Percentiles } & 2,0 & 12,5 & 1,0 & 1,0 \\
\hline & 3,0 & 22,0 & 3,0 & 2,0 \\
\hline & 5,5 & 26,0 & 6,3 & 3,0 \\
\hline
\end{tabular}

TABLA 4: Perfil de la muestra para participantes de los planes

\begin{tabular}{|c|c|c|c|c|}
\hline & $\begin{array}{l}\text { Número de } \\
\text { participantes } \\
\text { activos }\end{array}$ & $\begin{array}{l}\text { Número de } \\
\text { participantes } \\
\text { asistidos }\end{array}$ & $\begin{array}{l}\text { Numero de } \\
\text { pensionistas }\end{array}$ & $\begin{array}{l}\text { Madurez (activos/ } \\
\text { asistidos+pensionistas) }\end{array}$ \\
\hline Promedio & 8182 & 3428 & 1259 & 36,51 \\
\hline Desviación Estándar & 14218 & 9073 & 3821 & 93,82 \\
\hline Mínimo & 1 & 0 & 0 & 1,01 \\
\hline Máximo & 80120 & 54393 & 24675 & 686,00 \\
\hline Percentiles & 1259 & 108 & 25 & 2,15 \\
\hline 50 & 2927 & 557 & 122 & 3,82 \\
\hline 75 & 8927 & 2614 & 734 & 22,36 \\
\hline
\end{tabular}

TABLA 5: Perfil de la muestra para número de empleados y tercerización

\begin{tabular}{|c|c|c|c|c|c|}
\hline & & $\begin{array}{l}\text { Número de } \\
\text { empleados en } \\
\text { la fundación }\end{array}$ & $\begin{array}{l}\text { Gestión de } \\
\text { los activos } \\
\text { tercerizada }\end{array}$ & $\begin{array}{l}\text { Gestión del } \\
\text { pasivo } \\
\text { tercerizada }\end{array}$ & $\begin{array}{l}\text { Gestión administrativa } \\
\text { tercerizada }\end{array}$ \\
\hline \multicolumn{2}{|l|}{ Promedio } & 65,52 & 56,60 & 21,52 & 15,65 \\
\hline \multicolumn{2}{|l|}{ Moda } & 0,00 & 100,00 & 0,00 & 0,00 \\
\hline \multicolumn{2}{|c|}{ Desviación Estándar } & 14218 & 9073 & 3821 & 93,82 \\
\hline \multicolumn{2}{|c|}{ Mínimo } & 0,00 & 0,00 & 0,00 & 0,00 \\
\hline \multicolumn{2}{|l|}{ Máximo } & 1237,00 & 100,00 & 100,00 & 100,00 \\
\hline \multirow[t]{3}{*}{ Percentiles } & 25 & 3,00 & 11,75 & 0,00 & 0,00 \\
\hline & 50 & 14,00 & 69,50 & 0,00 & 0,00 \\
\hline & 75 & 53,00 & 94,75 & 45,00 & 20,00 \\
\hline
\end{tabular}


TABLA 6: Perfil de la muestra para composición de los consejos

\begin{tabular}{|l|r|r|r|r|r|r|}
\hline \multirow{2}{*}{} & \multicolumn{3}{|c|}{$\begin{array}{c}\text { Numero de Miembros en el } \\
\text { Consejo deliberativo }\end{array}$} & \multicolumn{3}{c|}{$\begin{array}{c}\text { Número de consejeros } \\
\text { elegidos por los participantes }\end{array}$} \\
\cline { 2 - 7 } & TOTAL & Privadas & Estatales & \multicolumn{1}{c|}{ TOTAL } & Privadas & Estatales \\
\hline Promedio & 6,17 & 6,52 & 5,76 & $36,79 \%$ & $25,16 \%$ & $50,00 \%$ \\
\hline Moda & 6 & 3 & 6 & $50,00 \%$ & $33,00 \%$ & $50,00 \%$ \\
\hline Desviación Estándar & 2,42 & 3,19 & 0,72 & $20,07 \%$ & $18,66 \%$ & $11,79 \%$ \\
\hline
\end{tabular}

TABLA 7: Perfil de la muestra para composición de la dirección

\begin{tabular}{|c|c|c|c|}
\hline $\begin{array}{l}\text { TOTAL } \\
\text { patrocinador estatal } \\
\text { y privado }\end{array}$ & $\begin{array}{l}\text { Número de } \\
\text { miembros en } \\
\text { la Direccion }\end{array}$ & $\begin{array}{l}\text { Número de representantes } \\
\text { de los participantes en } \\
\text { en la Dirección }\end{array}$ & $\begin{array}{l}\text { Porcentaje de } \\
\text { directores elegidos } \\
\text { por los participantes }\end{array}$ \\
\hline Promedio & 3,41 & 0,36 & $10,31 \%$ \\
\hline Moda & 3 & 0 & $0,00 \%$ \\
\hline Desviación Estándar & 0,77 & 0,71 & $20,14 \%$ \\
\hline Mínimo & 2 & 0 & $0,00 \%$ \\
\hline Máximo & 6 & 3 & $100,00 \%$ \\
\hline Percentiles & 3 & 0 & $0,00 \%$ \\
\hline 50 & 3 & 0 & $0,00 \%$ \\
\hline 75 & 4 & 1 & $25,00 \%$ \\
\hline
\end{tabular}

En la secuencia se presentan los resultados que se obtuvieron en el procesamiento de las respuestas, tanto las informaciones descriptivas, como los resultados de las pruebas estadísticas realizadas para la evaluación de la existencia de diferencias significativas entre los subgrupos formados por los segmentos definidos para las características que se presentaron en el cuadro 2. Para la comparación de los segmentos se aplicaron pruebas no paramétricas de independencia de los promedios, utilizándose la rutina Crosstab en el SPSS versión 10.0, basados en el coeficiente Phi, para las variables binarias referentes a la existencia o no de un instrumento, y la prueba chi-cuadrado de Pearson, con corrección de continuidad de Yates, para las demás variables categóricas. Para las variables continuas se utilizó la prueba de independencia de promedios; la verificación de la homogeneidad de las varianzas se obtuvo por la prueba de Levene.

La presentación de los resultados a continuación se organizó de acuerdo con las categorías analíticas definidas. Se analizan en la secuencia apenas los casos en que hubo diferencia significativa entre los segmentos utilizados.

\subsection{Presiones de patrocinadores y participantes}

Para la primera categoría analítica establecida - presiones de patrocinadores y participantes - dividida en tres constructos y 18 variables, los resultados según el porcentaje válido de utilización de los instrumentos destacados se presentan en la tabla 8. 
TABLA 8: Instrumentos de monitoreo y control utilizados por los patrocinadores

\begin{tabular}{|l|l|l|l|l|l|l|c|}
\hline INSTRUMENTO & Uso (\%) & Plan & Orig & Activ & Núm & Edad & Madu \\
\hline Existencia de planeamiento estratégico & 85,2 & & & & & & \\
\hline $\begin{array}{l}\text { Metas exclusivamente financieras en el } \\
\text { planteamiento }\end{array}$ & 34,8 & & & $* * * *$ & & $* * * *$ & $* *$ \\
\hline $\begin{array}{l}\text { Existencia de mecanismo formal de evaluación } \\
\text { del gestor por el consejo deliberativo }\end{array}$ & 24,7 & & & & & & \\
\hline $\begin{array}{l}\text { Elección del actuario sujeta a la aprobación del } \\
\text { consejo deliberativo o patrocinador }\end{array}$ & 66,7 & & $* *$ & & & & $*$ \\
\hline $\begin{array}{l}\text { Elección de consultoría actuarial sujeta a la } \\
\text { aprobación del consejo deliberativo o del } \\
\text { patrocinador }\end{array}$ & 66,7 & & $*$ & & & & $* * * *$ \\
\hline $\begin{array}{l}\text { Elección de gestores financieros sujeta a la } \\
\text { aprobación del consejo deliberativo o del } \\
\text { patrocinador }\end{array}$ & 60,00 & & $*$ & & & & \\
\hline $\begin{array}{l}\text { Elaboración de informes encaminados a la } \\
\text { patrocinadora además de los legales }\end{array}$ & 61,3 & & $* * *$ & & $*$ & & \\
\hline $\begin{array}{l}\text { Realización de auditorías además de las } \\
\text { obligatorias }\end{array}$ & 54,3 & $* *$ & & $* * * *$ & & $*$ & $*$ \\
\hline
\end{tabular}

Significativa a $0,10^{*}$, a $0,05^{* *}$, a $0,01^{* * *}$, y a $0,001^{* \star \star *}$

\subsubsection{Instrumentos de monitoreo y control utilizados por los patrocinadores}

La elaboración de un planeamiento estratégico es un instrumento fundamental para definir los objetivos y prioridades del fondo de pensión y la forma como se pretende alcanzarlos. Se configura no solo en un instrumento de gestión sino en un mecanismo de gobernanza que permite a patrocinadores y participantes establecer cómo sus objetivos y expectativas serán atendidos. Los resultados que se obtuvieron, como se muestran en la tabla 8, denotan una amplia utilización de esta herramienta, aunque no sea posible evaluar cómo este planeamiento estratégico se elabora ni cómo los objetivos se definen.

El uso de metas exclusivamente financieras en las entidades que afirmaron realizar un planeamiento estratégico se mostró significantemente diferente en distintas situaciones. Fondos con menores volúmenes de activos de inversiones tienden a utilizar únicamente metas financieras - en el 52,9\% de los casos, contra apenas el 17,1\% de los mayores -, mientras que los mayores tienden a utilizar también metas asociadas a la gestión, probablemente en virtud de las exigencias de su estructura administrativa más elaborada. Fondos más nuevos, con existencia de hasta 20 años, también fueron asociados a una elección por metas solamente financieras, en la razón del $50 \%$ contra apenas el $20 \%$ de los más antiguos. Divergencias también se presentaron con relación a la madurez. En el 47,2\% de las entidades en situación de desarrollo las metas son exclusivamente financieras, en contraposición con el 21,2\% de aquellas con planes en fase de madurez. En resumen, este dato parece evidenciar que una 
mayor estructuración del fondo, sea debido a su madurez, al tiempo de existencia, o al porte, lleva al uso de un conjunto más amplio de metas, no limitándose apenas a las financieras.

La existencia de un mecanismo formal de evaluación del gestor a la disposición del consejo deliberativo representa una práctica poco utilizada en el sistema, sea cual sea la característica del fondo, aunque la literatura contemporánea de gobernanza corporativa, que trata de la relación entre consejos y gestores, converja al destacar la importancia de esta evaluación (OECD, 2004). Este es un instrumento de fundamental importancia, tanto para patrocinadores y participantes, en el que pueden consolidar lo que esperan del gestor en términos de agregación de valor, como también de este mismo gestor, por traerle mayor tranquilidad sobre cómo estará siendo evaluado.

Una forma de monitoreo y control del patrocinador sobre los gestores ocurre por la elección de los responsables para conducir los procedimientos actuariales y de gestión financiera. La elección del actuario está sujeta a la aprobación del consejo deliberativo o del patrocinador en el $66,7 \%$ de los casos, principalmente en entidades con patrocinadores privados (el 77,3\% versus el $54,1 \%$ ) y en etapas más avanzadas de madurez (el 76,3\% versus el $58,1 \%$ ), situación similar a la que ocurre en la elección de la consultoría actuarial. La certificación de la elección de gestores financieros por el consejo deliberativo o por el patrocinador se mostró diferente apenas por el origen del patrocinador. Fondos con predominio de patrocinador estatal someten esta elección en el 68,25 \% de los casos, mientras que los privados apenas en el $50 \%$.

En el $75 \%$ de los fondos con patrocinador privado se producen más informes para el patrocinador que aquellos exigidos por la legislación, lo que ocurre en apenas $44,4 \%$ de los estatales, permitiendo suponer la existencia de cuestiones adicionales de control. Fue estadísticamente significativa también la diferencia presentada en esta producción de informes por fondos con tres o más patrocinadores, que en el $69,8 \%$ de los casos producen otros informes además de los exigidos, frente al 51.4\% de las demás entidades, con 102 patrocinadores. Una hipótesis para explicar esta diferencia es que, en virtud de la amplitud y variedad del conjunto de interesados de los fondos multipatrocinados hay un cobro mayor por información y rendición de cuentas.

Cuando se les consultó si el fondo de pensión realizaba otras auditorías - sea por órgano interno, por auditores del patrocinador o a través de empresa de auditoría tercerizada además de aquellas exigidas por la legislación, los encuestados evidenciaron el área de mayor ocurrencia de diferencias significativas entre los segmentos analizados. Las respuestas apuntaron que entidades con planes en la modalidad beneficio definido (el $65 \%$ versus el 
$41 \%$ ), de mayor porte en cuanto al volumen de activos (el 73,2\% versus el 35,0\%), con 22 años o más de existencia (el 63,4\% versus el $45,0 \%$ ) y más maduras en la relación entre asistidos y activos (el $65,8 \%$ versus el $44,2 \%$ ), tienden a usar más intensamente mecanismos adicionales de auditoría. Probablemente, este hecho se explica por la mayor complejidad de estos fondos.

\subsubsection{Influencia directa de los participantes en la gestión}

La influencia de los participantes sobre la definición de los objetivos estratégicos y sobre la gestión de la organización ocurre, principalmente, por la participación en sus órganos estatutarios y por el ejercicio organizado de presión, en general por la constitución de una asociación de participantes del plan. Estas asociaciones tienen como beneficio a la gobernanza, la capacidad de minimizar el llamado "efecto auto-stop", [o del que se aprovecha] (free rider) resultante del bajo estímulo individual al acompañamiento de la gestión. Ocurre también en las cuestiones de gobernanza corporativa en empresas abiertas, cuando pequeños accionistas tienen que incurrir en gastos para acompañar la gestión de la empresa pero no consiguen, individualmente, capturar directamente los beneficios obtenidos por este acompañamiento.

El análisis de la relación entre consejeros deliberativos representantes de los participantes y del patrocinador se realizó separadamente para las entidades con patrocinadores privados y con estatales en virtud de las exigencias de la Ley Complementaria 108, que establece las estructuras de gobernanza en el consejo y la representación de los participantes en los fondos estatales, y de la Ley Complementaria 109, que regula el asunto para los fondos con patrocinadores privados.

TABLA 9: Instrumentos de influencia directa de los participantes

\begin{tabular}{|l|l|l|l|l|l|l|l|}
\hline INSTRUMENTO & Uso (\%) & Plan & Orig & Activ & Núm & Edad & Madu \\
\hline $\begin{array}{l}\text { Porcentaje de representantes de los participantes } \\
\text { en el consejo deliberativo (mediana) }\end{array}$ & & & & & & & \\
\hline Fondos con patrocinador estatal (LC 108) & $50,0 \%$ & & & & & & \\
\hline Fondos con patrocinador privado (LC 109) & $33,3 \%$ & $*$ & & $* *$ & & $* * * *$ & $* * * *$ \\
\hline $\begin{array}{l}\text { Porcentaje de representantes de los participantes } \\
\text { en la dirección ejecutiva (mediana) }\end{array}$ & & & & & & & \\
\hline Fondos con patrocinador estatal (LC 108) & $0,0 \%$ & & & $* *$ & & $*$ & \\
\hline Fondos con patrocinador privado (LC 109) & $0,0 \%$ & & & & $* *$ & & $* *$ \\
\hline Existencia de asociación de los participantes & $54,3 \%$ & $* *$ & $* * *$ & $* * * *$ & & $* * * *$ & $* * * *$ \\
\hline
\end{tabular}


Conforme a los datos, la existencia de una asociación de participantes tiende a ser constituida principalmente por individuos vinculados a fondos con predominio de planes en la modalidad BD (el $65 \%$ versus el $41 \%$ ), con patrocinio de órganos estatales (el 78,4\% versus el $34,1 \%$ ), de gran porte (el $70,7 \%$ versus el $47,5 \%$ ), antiguos (el $82,9 \%$ versus el $25 \%$ ) y con indicadores de madurez más elevados (el $78,9 \%$ versus el $32,6 \%$ ). El conocimiento empírico del sistema sostiene estos resultados, una vez que es razonable esperar que fondos vinculados a entes públicos, más antiguos, y con mayor número de participantes, hayan traído para este contexto una capacidad de articulación para el ejercicio de sus intereses, desarrollada en la relación funcional con la empresa patrocinadora y transferida para la relación con el fondo. Empleados de empresa estatal, por ejemplo, tienen tradición de organizarse para la reivindicación de derechos laborales y aumentos de sueldo, de forma que esta capacidad organizativa puede ser naturalmente transferida para su relación con otras organizaciones de vínculo colectivo de estos empleados, a ejemplo de los fondos de pensión.

Como era esperable, y en virtud de la adecuación a la Ley Complementaria 108 que determina el número máximo de consejeros y la participación de los miembros representantes de los participantes, no hubo diferencias entre los segmentos de los fondos que tienen entes públicos como patrocinadores en relación con la participación en el consejo deliberativo. Se observa, por no ser regulado por la Ley, que entre estos fondos, aquellos con mayores volúmenes de activos apuntaron una participación del $18 \%$, en promedio, de directores representantes de los participantes, frente a apenas el $2 \%$ de ocurrencia en los fondos pequeños, situación semejante a la presentada en la segmentación por edad de los fondos, con una relación del $16 \%$ en los más antiguos para el $4 \%$ en los más nuevos.

En el segmento de fondos de pensión con patrocinador privado la predominancia de plan en la modalidad BD está asociada con un mayor porcentaje de consejeros representantes de los participantes, que es del $33 \%$, como está previsto en la LC 109, en contra del $22 \%$ en los $C D$, lo que indica, asimismo, un proceso de adecuación de estas entidades a la legislación.

El tiempo de existencia del fondo de pensión se muestra también como significativamente asociado a la representatividad de los participantes en el consejo, una vez que entidades con 22 años o más de existencia tienen el 38\% contra el 20\% de las más nuevas. Fondos más maduros, probablemente también los más antiguos, tienen el $37 \%$ en contra del $18 \%$ de los demás, asociación que se repite en el ámbito de la dirección, con el 18\% en contra del $3 \%$. El número de patrocinadores se relaciona con la participación en la Dirección. Fondos con hasta 2 patrocinadores tienen un promedio del $16 \%$ contra el $3 \%$ de aquellos con 3 o más. 


\subsubsection{Control indirecto}

Mientras que el control directo se configura por la participación de las organizaciones en el consejo, el control indirecto se caracteriza por formas alternativas para asegurar determinados comportamientos y mantener parte del control del proceso decisorio. Son ejemplos el control de los gastos y la elección de ejecutivos. Así, la responsabilidad por los costos administrativos de los fondos y la indicación para los cargos ejecutivos de los empleados de sus propios cuadros son mecanismos típicos de control indirecto utilizados en este sistema.

TABLA 10: Control indirecto

\begin{tabular}{|l|l|l|l|l|l|l|l|}
\hline INSTRUMENTO & Uso (\%) & Plan & Orig & Activ & Núm & Edad & Madu \\
\hline $\begin{array}{l}\text { Costeo de los gastos administrativos exclusivamente } \\
\text { por el patrocinador }\end{array}$ & 44,3 & $* * *$ & $* * *$ & $* *$ & & $* * *$ & \\
\hline $\begin{array}{l}\text { Primer gestor oriundo de los cuadros del } \\
\text { patrocinador }\end{array}$ & 81,0 & & & & & $* *$ & \\
\hline $\begin{array}{l}\text { Primer Gestor con dedicación exclusiva al fondo de } \\
\text { pensión. }\end{array}$ & 78,3 & & **** & & & *** & ** \\
\hline $\begin{array}{l}\text { Existencia de comités de análisis con anterioridad } \\
\text { a la deliberación de la dirección. }\end{array}$ & 59,5 & & & & & & \\
\hline
\end{tabular}

Significativa a $0,10^{*}$, a $0,05^{* *}$, a $0,01^{* * *}$, y a $0,001^{* * * *}$

Como lo evidencian los resultados, los gastos administrativos costeados exclusivamente por el patrocinador ocurren con frecuencia significativamente mayor en las entidades con predominio de planes CD (el $62,2 \%$ versus el $27,5 \%$ ), en fondos privados (el $66,7 \%$ versus el 18,9\%), en fondos con menores volúmenes de activos de inversión (el 57,5\% versus el $20,8 \%$ ), y en los más nuevos (el 59,0\% versus el 30,0\%). Una explicación para estos resultados es que, con el objetivo de que el plan se vuelva más atractivo para sus empleados, el patrocinador subsidia los costos administrativos.

En fondos más antiguos es más probable encontrar el primer gestor ejecutivo oriundo de los cuadros del patrocinador (el 90,0\% versus el 71,8\%). Este dato es bastante expresivo para mostrar la influencia de la empresa patrocinadora sobre el fondo y refuerza argumentos anteriores de este trabajo, en cuanto a los cambios que serán exigidos para la migración de los fondos de pensión para un modelo basado en multipatrocinio y multiplanes, que permitirán obtener una mejor eficiencia en el costeo y en las inversiones. El dato apunta también hacia un posible problema en cuanto a la profesionalización de las entidades. El hecho de que los gestores pertenecen al cuadro de la patrocinadora presupone que es allí que construyen sus carreras y donde privilegian desarrollar su competencia, conocimiento y trayectoria profesional. Así, la práctica de traer para administrar el fondo a un profesional con intereses en otra área 
u organización puede ejercer influencia negativa sobre la profesionalización de este sistema, una vez que crea pocos incentivos para que estos ejecutivos den su mejor esfuerzo a la gestión del fondo. Traer al gestor del fondo de los cuadros de la patrocinadora tiene, por lo tanto, un efecto positivo para reducir los problemas de agencia, pero negativo en cuanto a la mejora de la eficiencia de las entidades.

En el 78,3\% de los casos válidos el gestor tenía dedicación en tiempo integral a la entidad, siendo más frecuente que esto ocurra en fundaciones vinculadas a empresas estatales sujetas a la Ley Complementaria 108 (el 97,0\% versus el 61,1\%), más antiguas (el 92,1\% versus $61,3 \%$ ) y con planes más maduros (el $90,9 \%$ versus el $66,7 \%$ ).

En la mayor parte de las entidades participantes de la investigación (el 59,5\%), los asuntos están sujetos al análisis previo de un comité antes de ser sometidos a la apreciación de la dirección ejecutiva. No hubo, con todo, diferencias significativas en esta práctica entre los segmentos analizados.

\subsection{Percepción de control por el gestor}

Al contrario de la categoría anterior, esta categoría analítica no trata de datos factuales, sino de la impresión causada en los ejecutivos de los fondos por la utilización de mecanismos de monitoreo y control. Cupo al primer gestor del fondo señalar, en su respuesta al cuestionario, su visión particular sobre las cuestiones y temas propuestos. Este análisis tiene como fundamento que el control de los problemas de agencia no se relaciona apenas con el uso de herramientas y prácticas, sino, sobre todo, con el efecto que causan sobre el comportamiento del gestor, indicado por su percepción de control. 0 sea que los mecanismos de monitoreo utilizados por el principal tendrán su efectividad aumentada en la medida que la sensación de su influencia por el gestor como moderador de su comportamiento sea mayor.

\subsubsection{Percepción del monitoreo}

TABLA 11: Percepción del monitoreo por el gestor

\begin{tabular}{|l|c|c|}
\hline \multicolumn{3}{|c|}{ Intensidad en el análisis de los informes de acompañamiento } \\
\hline \multirow{4}{*}{ Prácticamente no usa } & Por el Consejo Deliberativo & Por el Consejo Fiscal \\
\cline { 2 - 3 } Baja intensidad & 3,7 & 5,3 \\
\cline { 2 - 3 } Mediana intensidad & 6,2 & 3,9 \\
\cline { 2 - 3 } Alta intensidad & 33,3 & 23,7 \\
\cline { 2 - 3 } & 56,8 & 67,1 \\
\hline
\end{tabular}


Para el $57 \%$ de los fondos de la muestra el consejo deliberativo analiza los informes de acompañamiento encaminados por la dirección de forma altamente intensa, presuponiendo con esto que haya un esmerado análisis de sus informaciones, porcentaje que es aún mayor cuando se trata de los análisis realizados por el consejo fiscal. En ningún caso fue posible rechazar la hipótesis nula entre los agrupamientos determinados por los segmentos, lo que significa que la intensidad del monitoreo por los consejos se percibe de forma semejante por gestores de fondos con características diversas.

\subsubsection{Percepción de la influencia de los participantes en la gestión}

TABLA 12: Percepción de la influencia de los participantes en la gestión

\begin{tabular}{|l|l|l|l|l|l|l|l|}
\hline INSTRUMENTO & Uso (\%) & Plan & Orig & Activ & Núm & Edad & Madu \\
\hline $\begin{array}{l}\text { Conocimiento de los participantes de los resultados } \\
\text { financieros }\end{array}$ & $\begin{array}{l}5,00 \\
\text { (mediana) }\end{array}$ & & & & & & \\
\hline $\begin{array}{l}\text { Conocimiento de los participantes de la gestión del } \\
\text { fondo }\end{array}$ & $\begin{array}{l}5,00 \\
\text { (mediana) }\end{array}$ & & & & & & \\
\hline $\begin{array}{l}\text { Los participantes acompañan el desempeño y buscan } \\
\text { Intensidad de las presiones de la asociación de }\end{array}$ & 25,9 & & $*$ & **** & ** & ** & \\
\hline participantes & & & **** & *** & ** & **** & **** \\
\hline No hay asociación de participantes & 45,7 & & & & & & \\
\hline Presiones poco significativas & 9,9 & & & & & & \\
\hline Presiones medianamente significativas & 28,4 & & & & & & \\
\hline Presiones muy significativas & 16,0 & & & & & & \\
\hline
\end{tabular}

Significativa a $0,10^{*}$, a $0,05^{* *}$, a $0,01^{* * *}$, y a $0,001^{* * * *}$

Para los dos primeros ítems, conocimiento de los participantes de los resultados financieros y de la gestión, se solicitó al gestor que estableciera una puntuación progresiva del 1 al 7 , en una escala donde el 7 significaba el nivel de conocimiento más elevado. Los gestores atribuyeron el nivel 5, dado por la mediana, al conocimiento de los participantes sobre los resultados financieros y sobre gestión de la fundación, nivel este que también representó la moda de ambas distribuciones. No fueron identificadas diferencias significativas para los segmentos analizados.

En el caso de los fondos de pensión en que se registraba la existencia de una asociación de participantes, los gestores afirmaron en apenas el 25,9\% de las respuestas que los participantes de los planes acompañaban el desempeño de la fundación y trataban de ejercer influencia. El activismo de los participantes es percibido por los gestores de los fondos estatales (el $61,9 \%$ versus el 38,1\%), fondos grandes (el 85,7\% versus el 14,3\%), con 3 o más patrocinadores (el $76,2 \%$ versus el $23,8 \%$ ) y más antiguos (el $71,4 \%$ versus el $28,6 \%$ ). En 
lo que se refiere al activismo de estas asociaciones existentes, las respuestas indicaron que este tiende a ser ejercido de forma más intensa en los fondos patrocinados por órganos estatales, con mayores volúmenes de recursos, más antiguos y con mayor madurez.

\subsubsection{Influencia de otras organizaciones}

El mercado de actuación de una determinada organización ejerce un mecanismo externo, o de control indirecto, de minimización de los problemas de agencia. En el caso de los fondos, es razonable suponer que los resultados positivos de otros fondos de pensión, o incluso de fondos de inversión, funcionen como benchmarks [puntos de referencia] para los gestores, representando un mecanismo indirecto de presión. Un efecto isomorfo sobre el sistema también debe ser observado, imponiendo a los fondos la utilización de prácticas difundidas en el ámbito del propio sistema o utilizadas por las patrocinadoras, efecto que está previsto por la denominada teoría institucional (Meyer y Rowan, 1977; DiMaggio y Powell, 1983; Scott, 1987).

TABLA 13: Influencia de otras organizaciones

\begin{tabular}{|l|l|l|l|l|l|l|l|}
\hline INSTRUMENTO & Uso (\%) & Plan & Orig & Activ & Núm & Edad & Madu \\
\hline $\begin{array}{l}\text { Influencia de los resultados de otros fondos de } \\
\text { pensión y de inversión sobre la gestión }\end{array}$ & $\begin{array}{l}4,00 \\
\text { (mediana) }\end{array}$ & & & & & \\
\hline $\begin{array}{l}\text { Influencia de las prácticas de gestión de otros } \\
\text { fondos }\end{array}$ & 90,0 & & & & & & \\
\hline $\begin{array}{l}\text { Influencia de las prácticas de gestión del patrocinador } \\
\text { (algunas veces o en la mayoría de las veces) }\end{array}$ & 75,1 & & $* * * *$ & & & & \\
\hline
\end{tabular}

Significativa a $0,10^{*}$, a $0,05^{* *}$, a $0,01^{* * *}$, y a $0,001^{* * * *}$

En el cuestionario se solicitó que se evaluara la influencia sobre su administración de los resultados obtenidos por otros fondos de pensión y organizaciones con actividades semejantes, tales como planes abiertos de previsión y fondos de inversiones. Estas presiones tienen una naturaleza mimética porque favorecen la legitimación de las prácticas del gestor y de la organización. Las respuestas que se obtuvieron apuntaron hacia un elevado grupo de contestadores que atribuyen poca expresión - nota 1 en una escala de 7 puntos - a esta influencia, equivalente al $19 \%$ de la muestra. De los 79 fondos que contestaron a esta cuestión, 28 atribuyeron nota igual o menor que 3, indicando la poca importancia dada a los resultados de otros fondos u organizaciones semejantes. La prueba de independencia de los promedios no apuntó ninguna diferencia significativa entre los segmentos en foco.

Limitados a analizar la influencia de prácticas de gestión e innovaciones de éxito adoptadas por un fondo de pensión, el $90 \%$ afirmó considerar que estas ejercen influencia sobre sus 
modelos. Se señaló también que en el $24 \%$ de los casos se adoptan en la mayoría de las veces las prácticas de gestión del patrocinador y en el $51 \%$ de los casos, solo algunas veces, resultado este que debe ser cotejado con la información anterior sobre el origen, si consideramos que en el $81 \%$ de los casos el primer gestor provenía de los cuadros de la empresa patrocinadora.

Fondos vinculados a entes privados son más propensos a seguir en la mayoría de las veces las prácticas del patrocinador, que los estatales (el $46,4 \%$ versus el $8,3 \%$ ). Mientras que estos afirmaron que en el $36,1 \%$ de los casos, raramente o nunca utilizaban estas prácticas, en los fondos con patrocinadores privados esta proporción quedó en el 15,9\%.

\section{Consideraciones finales}

Este estudio tuvo el objetivo de comprender las prácticas de gobernanza y gestión utilizadas por los fondos de pensión brasileños para administrar las expectativas, influencias y relaciones con sus participantes, patrocinadores y ejecutivos. La evaluación tuvo como motivación que los fondos se encuentran en el umbral de un cambio en la configuración del sistema de previsión complementaria en Brasil, frente a factores como la reducción de las tasas de intereses, la madurez de las organizaciones del sistema de previsión cerrada, la difusión de los institutos del multipatrocinio y multiplan, el crecimiento de la competitividad de las empresas de previsión complementaria abierta y la oferta de planes complementarios de previsión a los servidores públicos. Ante tales cambios, es fundamental entender la dinámica actual de la organización de estos fondos para sostener empíricamente la construcción de propuestas de desarrollo de su gobernanza e instrumentos de gestión.

Los análisis realizados, sostenidos por los resultados de la investigación aplicada junto a los administradores de los fondos de pensión brasileños, permitieron evidenciar la necesidad de una adecuación de los instrumentos de monitoreo y control a características particulares de los fondos de pensión brasileños. Lo que el análisis de los cuestionarios evidenció fue una significativa diferencia entre grupos de fondos de pensión relativamente a la utilización de los instrumentos de presión del principal, no siempre alineados con las propuestas teóricas.

Tomando por base las propuestas de la teoría de la agencia, cabe destacar que la intensidad del monitoreo, como se ha evidenciado por los instrumentos utilizados en la gobernanza de los fondos, no se mostró asociada al riesgo incurrido por el principal. Así, aunque el riesgo involucrado fuera menor, los participantes de planes en la modalidad beneficio definido mostraron una actuación mucho más intensa en el acompañamiento de la gestión de los fondos, en términos del conjunto de mecanismos utilizados en el monitoreo y control, hecho corroborado también por la percepción de los gestores. Fue posible registrar, con importancia 
estadística, un uso más amplio de mecanismos de monitoreo por los patrocinadores en estos planes, convergente con el mayor riesgo asumido; entre tanto esta diferencia no se registró en cuanto a la actuación del consejo.

Además, y probablemente relacionado con la observación anterior, los participantes de fondos de pensión que presentan niveles de madurez más elevados en sus planes exhiben una capacidad mayor de monitoreo del gestor. Es posible suponer que este hecho refleja la capacidad organizativa de estos participantes, adquirida a lo largo de la existencia del fondo, pero no la necesidad de monitoreo prevista en la teoría, teniendo en vista que en estos fondos un número mayor de participantes ya aseguró sus derechos. De esta forma, excepto en la ocurrencia de sucesivos resultados financieros negativos, jubilados y pensionistas tienen menos riesgo vinculado al plan.

La asociación de estos resultados con los análisis sobre el contexto de actuación de los fondos apunta hacia la exigencia de una revisión de las bases teóricas utilizadas para la elaboración de los modelos de gobernanza de los fondos de pensión, una vez que las premisas de la teoría de la agencia, esenciales para la construcción de los modelos de gobernanza corporativa (Shleifer y Vishny, 1997), no se confirman en el ambiente altamente regulado de la previsión complementaria cerrada. Asimismo, las barreras de salida enfrentadas por los participantes y por los patrocinadores, y fundamentales a las prácticas asociadas al modelo anglosajón de gobernanza (Lethbridge, 1997), limitan el poder de disciplina de las fuerzas de mercado previsto por la teoría.

Otra consideración que debe hacerse es que los problemas de gobernanza enfrentados por participantes y patrocinadores son estructuralmente diferentes, ya que estos se sitúan de forma ambivalente como principal o como agente, mientras que el gestor de la entidad, típicamente, es también un participante históricamente comprometido con el desempeño de la organización. Separar estructuralmente el fondo de pensión del patrocinador no siempre es tarea simple, como se hace evidente al verificarse que el $14 \%$ de los fondos que contestaron ni siquiera tenía empleados, y el $44 \%$ de sus gastos administrativos estaba totalmente cubierto por el patrocinador.

El sistema de fondos de pensión tiene una larga historia en el país, si se considera que más de la mitad de los fondos de la muestra estaba con más de 21 años de existencia cuando se realizó la investigación, en 2004, o sea, 27 años después de la ley que normó al sector, indicando la intensidad de creación de los fondos provocada por esta ley. Cabe mencionar también que eventos diversos ocurridos en los últimos años - como cambios de legislación, presiones políticas para inversiones, y privatizaciones - promovieron una gran unión de estas 
organizaciones en torno a intereses comunes, y posiblemente contribuyeron para la alineación de las prácticas e instrumentos utilizados para la solución de problemas compartidos en el sector, lo que, a su vez, pudo haber ejercido influencia en la semejanza de las percepciones de los gestores sobre los efectos de los sistemas de gobernanza.

Un sistema que tiene recursos financieros superiores al $16 \%$ del Producto Interno Bruto del país y que responde por la calidad de vida de cerca de 2,4 millones de individuos, justifica todo un interés y esfuerzo de desarrollo de acciones que fortalezcan su crecimiento. Las transformaciones de su contexto de actuación están exigiendo una mayor comprensión de las formas de contestar a las nuevas necesidades, principalmente de naturaleza económica, de estructuración y competitiva, razones que configuran el sistema de fondos de pensión como un ambiente fecundo para el fortalecimiento de buenas prácticas de gobernanza y para el avance de las teorías que les dan soporte. En este sentido, el actual estudio buscó presentar su contribución al describir las principales prácticas utilizadas en el monitoreo y control de los fondos y ofrecer subsidios a la construcción de modelos de gobernanza e instrumentos de gestión que atiendan a las exigencias particulares de estas organizaciones.

\section{Referencias bibliográficas:}

ABRAPP - Associação Brasileira das Entidades Fechadas de Previdência Complementar. 2001. Consolidado Estatístico mar. 2001. En www.abrapp.org.br 14-7-2007.

ABRAPP - Associação Brasileira das Entidades Fechadas de Previdência Complementar. 2007. Consolidado Estatístico mar. 2007. En www.abrapp.org.br 14-7-2007.

Balassiano, M.; Elvira. C. F. Ventura; Joaquim R. Fontes Filho. 2003. Carreiras e Cidades: Existe um Melhor Lugar para se Fazer Carreira? Ponencia presentada em XXVII Encontro da Associação Nacional dos Programas de Pós-Graduação em Administração 21-24 Septiembre, Atibaia, SP, Brasil.

BRASIL. 2001a. Lei Complementar 109, de 29 de maio de 2001a. Dispõe Sobre o Regime de Previdência Complementar e dá Outras Providências.

BRASIL. 2001b. Lei Complementar 108, de 29 de maio de 2001. Dispõe Sobre a Relação Entre a União, os Estados, o Distrito Federal e os Municípios, suas Autarquias, Fundações, Sociedades de Economia Mista e outras Entidades Públicas e suas Respectivas Entidades Fechadas de Previdência Complementar, e dá outras Providências.

BRASIL. 2001c. Série Estudos: Previdência e Estabilidade Social: Curso Formadores em Previdência Social. Ministério da Previdência e Assistência Social. Secretaria de Previdência Social. Coleção Previdência Social, Volume 7. Brasília: MPAS/SPC. Delboni, Denise Poiani. 2003. A Previdência Complementar como Instrumento da Política de Recursos Humanos: um Estudo em Empresas do Setor Farmacêutico. Tesis (Doctorado en Administración) - Escola de Administração de Empresas de São Paulo, Fundação Getulio Vargas, São Paulo. 
DiMaggio, Paul J. y Walter W. Powell 1983. The Iron Cage Revisited: Institutional Isomorphism and Collective Rationality in Organizational Fields. American Sociological Review 48 (2): 147-160.

Eisenhardt, Kathleen M. 1989. Agency Theory: an Assessment and Review. Academy of Management Review 14 (1): 57-74.

Fama, Eugene F. y Michael C. Jensen. 1983. Agency Problems and Residual Claims. Journal of Law \& Economics 26 (2): 327-349.

FENAPREVI - Federação Nacional de Previdência Privada e Vida (2007). Dados Estatísticos Grupo Previdência complementar e VGBL - Março.

En http://www.fenaprevi.org.br/Site/secao/830.aspx 4-7-2007.

Impavido, Gregorio. 2002. On the Governance of Public Pension Fund Management (August 2002). World Bank Policy Research Working Paper No. 2878.

En http://ssrn.com/abstract=636241, 18-8-2004.

IPEA. 2006. Radar Social. En 5-7-2007.

Lethbridge, Eric. 1997. Governança corporativa. Revista do BNDES .8. 5-4-2007.

Meyer, John W. y Brian Rowan. 1977. Institutionalized Organizations: Formal Structure as Myth and Ceremony. American Journal of Sociology 83 (2): 340-363.

Shleifer, Andrei y Robert Vishny. 1997. A Survey of Corporate Governance. Journal of Finance 52: 737-783.

Joaquim Fontes Filho es Professor de la Escola Brasileira de Administração Pública e de Empresas da Fundação Getulio Vargas, no Rio de Janeiro - FGV/EBAPE. Doctor y Maestro en Administración por la FGV, se especializa en governanza corporativa, especialmente en lo que respecta a fondos de pensión. Coautor de Governança corporativa aplicada ao contexto empresarial brasileiro (Papel Virtual, 2004), recientemente ha publicado Planejamento estratégico da pequena e média empresa: aplicações no setor turístico (Publit, 2006)

E-mail: Joaquim.rubens@fgv.br 